capable of carrying the heavy responsibility of higher posts in government departments in the engineering field. From June 1955 recruitment to the Factory Inspectorate has been made continuous and as a result of this change almost all the accumulated vacancies were filled, though there were very few suitable candidates with engineering experience. Most successful candidates were arts graduates with little or none of that experience on the factory floor which, though not essential, would increase their value.

Arrangements by which the Commissioners are consulted in making acting promotions from the subprofessional to the professional classes of the Works Group and related classes of officers not eligible for open competitions continued to work smoothly; and a rather higher number of vacancies in the Executive Class than last year were filled from school leavers of $17 \frac{1}{2}-19$ years without lowering the minimum standard, but there were no suitable candidates to spare. The universities have welcomed the Commission's decision to invite a number of younger members of the Administrative Class to act as links between the Civil Service and their former universities or colleges, by standing ready to answer inquiries and by making occasional informal visits to talk to individuals, and the scheme was put into operation in November 1955.

\section{THE NATIONAL RESEARCH COUNCIL OF CANADA}

\section{REPORT FOR 1955-56}

$\mathrm{T}$ HE thirty-ninth annual report of the National Research Council of Canada covers the year 1955-56 and includes, besides the President's report and the financial statement, the annual report of Canadian Patents and Development, Ltd., for the year ended March 31, 1956*. An entirely new industry has been established in Canada, based on the Research Council's patent for oil additives to extend the life of lubricating oils, and the Corporation considers that the agreements promise substantial revenues. Development of the Cambron process for direct oxidation of ethylene to ethylene oxide progresses slowly, but an improved type of reactor is being tested which promises more efficient operation and lower costs of construction. During the year, the National Research Council, which now employs a scientific staff of 558 , all but six of whom are engaged in research, with a technical staff of 753 and 814 general service and administrative personnel, distributed 2.6 million dollars for pure research in the universities in 420 grants and 277 scholarships and dealt with 7,600 technical inquiries from Canadian industries. Of the research grants, 300,000 dollars was administered by the Atomic Energy Control Board.

In the Division of Applied Biology, a jacketed coldstorage room has been used with advantage to store fresh fruit and vegetables, and it has been found that the sticky layer on the outside of the cells of some helophilic bacteria is deoxyribonucleic acid, loss of which is related to the salt requirements of the * J'hirty-Ninth Annual Report of the National Research Council of
Canada, 1955-56. Pp. 50. (N.R.C. No. 3970.) (Ottawa : Queen's Canada, 1955-5 helophilic bacteria. Studies of rats during their acclimatization to cold showed that though heat production in shivering. continues at a high level, there is a reduction and finally a disappearance of shivering, and the possibility of fundamental changes in muscle behaviour is being investigated. The Atlantic Regional Laboratory at Halifax has investigated the fermentation of apple juice, storage of potatoes, preservation of cod fillets and made considerable progress in its study of the chemical com. position of pitch formed in pulp and paper mills. The Prairie Regional Laboratory at Saskatoon has almost completed its investigation of the major factors affecting the production of glycerol and arabitol by honey yeasts in deep tank fermentation and has converted starch and other carbohydrates to eyclic glycols by hydrogenolysis under mild conditions.

In the Department of Applied Chemistry considerable progress has been made in explaining the mechanism of formation of the initial products in the oxidation of iron and its alloys and in a study of the phase diagram of the calcium-silver system. The thermal cracking of heavy Canadian crude petroleum has been studied, and the effects of pressures up to several thousand atmospheres on the equilibria of the system carbon dioxide-benzene-benzoic acid. Methods of improving gravitational sedimentation have been examined and an inexpensive method of preparing water-resistant silica has been doveloped. In the Division of Pure Chemistry, the major interest of the Organic Chemistry Section is still the invosti. gation of alkaloids and much work has been done on their biogenesis as well as on their structure. The study of the rates of solvolysis of the alkyl benzenesulphonates and methane sulphonates continued, and sixty-four steroids have been synthesized and their infra-red spectra examined. Deuterated hydrocarbons have been synthesized by a new method and much information obtained on the reactions of $\mathrm{CF}_{\mathbf{3}}$ racticals by the photolysis of hexafluoroacetone. The mercury photosensitized decomposition of ethylene, propylene and the butylenes has been investigated with a fast flow system attached to a mass spectrometer and the self-diffusion of the chloride ion in alkali chlorides is being determined by a new technique, while considerable progress has been made in investigating the semi-conductor properties of single crystals of anthracene, and the sorption of undissociated acids has been shown to be a general property of fibres, such as wool, silk and nylon, which contain peptide bonds.

The Division of Applied Physics has successfully investigated means for reducing noise in industry, giving special attention to the couch noise of newsprint machines, for which a comprehensive solution has been provided in principle, and the work is now being applied to paper mill machinery. It is expected that the Canadian unit of electrical resistance will be established on a fundamental basis during 1956-57. Much attention has been given to problems presented by the anomalous drying of newsprint in paper mills, and in these investigations a resistance thermometer that is not affected by lead resistance has been developed. The newly established Interferometry Section evolved several new techniques and expects to give more attention to research and development in future. A new airborne controlled method of aerial triangulation of high accuracy and efficiency has been developed and comprehensive work done on the distortion characteristics of cameras 
used in photogrammetry. Research on the techniques of measuring high-intensity gamma-ray sources continued and also on the friction of ice.

The Division of Pure Physics continued to study the behaviour of cosmic rays as they penetrate matter, and measurements taken in 1954 and 1955 in two cruises, one to the Arctic and the other to the Antarctic, have now shown that the Earth's magnetic field as it affects cosmic rays differs considerably from that derived from surface geomagnetic measurements. Completion of work on the lowtemperature electrical and thermal conductivity of the alkali metals indicates that the fundamental theory is seriously inadequate and for thermal conductivity a new semi-theoretical expression has been derived which accounts well for data over a wide range of match. Investigation of the spectra of polyatomic free radicals produced by the flash method of photodecomposition continued and the rotational Raman spectra of benzene, allene, cyanogen, butatriene, diacetylene and dimethylacetylene have been photographed under high resolution and their moments of inertia determined. Some work has been completed on a rigorous treatment of the central field. independent-particle nuclear shell model on the basis of the variational principle, and crystal structure studies made of the isomorphous dihydrate of lithium, sodium and silver dithionates, of acridiene II and of some aliphatic dibasic acids and their potassium salts.

The Division of Medical Research in 1955 awarded 145 grants-in-aid of research, in addition to seven consolidated grants, totalling 652,056 dollars, and of these, thirty-one grants were for cardiovascular research, to which a proportion of certain consolidated grants is also devoted. A Canadian Heart Foundation is now to be established, and the Council, on the recommendation of the Advisory Committee on Medical Research, is creating a new category of medical research associate, six of whom were expected to be appointed in 1956 .

The Division of Building Research opened a small Atlantic Regional Station in Halifax during the year and the Prairie Regional Station at Saskatoon concentrated with laboratory studies of cold-weather building problems. The Fire Research Section continued its studies of major fires in the Ottawa area, field studies of housing problems were made in many parts of the country, regional soil temperature observations were further extended and the effects of frost were studied in connexion with the whole problem of winter construction. Much of the work of the Division of Mechanical Engineering continues to be related to defence, but that for industry is increasing. An investigation of the icing of helicopters was undertaken for the Royal Canadian Navy and instruments designed and constructed during the year have included a flame detector for use with gas turbines in flight or on the ground, devices and techniques for investigating 'howling' combustion, a wave profile recorder, preliminary designs for air-speed measuring devices for navigating helicopters and control systems for a pilot supersonic tunnel, a wave-making machine, and a shipmodel profiling machine.

About half the work of the Radio and Electrical Engineering Division is on defence projects. In preparation for the International Geophysical Year an automatic radar system was designed for recording the aurora and the prototype tested continuously for eight rnonths. Studies are being made of the fundamental electrical and optical properties of dielectric crystals, and a Czochralski-type furnace has been built to produce the superpure silicon single crystals needed for a study of silicon transistors. Fundamental antenna studies included development of a new type of two-dimensional slotted wave-guide array, the use of ferrites at microwave frequencies, and the performance of a slot in a dielectric-coated cylinder. A merchant marine radar of exceptionally good short-range definition and long-range performance has been developed and constructed, but the microwave position-fixing system developed for inshore survey use required certain modifications. An electrical thermometer has been designed which provides continuous indication of the temperature in freshwater lakes at various depths, and an investigation of the explosion hazard of static electricity generated by grain handling is almost complete. A radio survey in Banff and Yoho National Parks indicated that a system operating in the 152-174 Mc./s. band and consisting of two base stations and one automatic repeater station would provide communication cover to most of the warden stations and continuous coverage along the Trans-Canada Highway. The cardiac defibrillator-stimulator and electronic device developed for resuscitation of the heart from fibrillation is now being manufactured under licence and development of blood pressure measuring equipment for inclusion in the resuscitator continues.

\section{INDUSTRIAL ACCIDENTS}

$T$

HE annual report of the Chief Inspector of Factories for $1955^{*}$ records the lowest accidentrate yet achieved, although the number of accidents, 188,403 , was 1.2 per cent greater than in 1954, the factory population being $2 \cdot 5$ per cent higher and the number of factories with power 0.4 per cent greater than in 1954. Since 1953 the accident-rate for women has increased, and the Chief Inspector attributes this largely to the general rise in the number of women employed, of whom many are new to industry. $\mathrm{He}$ stresses the responsibility of management for special care to protect those entering industry for the first time and completely unfamiliar with their environment, as well as the importance of proper induction, training and supervision for young persons.

A separate chapter of the report reviews the changes in the rubber industry since 1922 in relation to the Indiarubber Regulations, 1955, prohibiting the use of carbon disulphide in the cold-cure process of vulcanizing in proofing cloth with rubber, which came into force during the year, and the Chief Inspector comments at greater length than usual on factory medical and nursing services. An outstanding feature of the year was the inception of a survey of conditions affecting health in all factories in Halifax, and of another survey of such conditions in the pottery industry. Another feature was the increased attention given to factory design. The Midland Regional Board for Industry sponsored some research into relative costs and merits of various types of factory premises, including the methods and costs of construction and the effect of the different types on production.

The increase in mechanization throughout industry generally is eliminating much heavy manual and

- Annual Report of the Chief Inspector of Factories for the year 1955. Pp. 275. (Cmd. 8.) (London: H.M. Stationery Office, 1956.) $9 s$. net. 